\title{
Thrombophilia and Recurrent Pregnancy Loss: Are we Still Loosing the Link at the $21^{\text {st }}$ Century?
}

\section{Raúl H. Morales-Borges*}

Ashford Institute of Hematology \& Oncology, USA

Recurrent Pregnancy Loss (RPL) refers to two or more failed pregnancies and the American Society for Reproductive Medicine suggests an assessment after each loss with a thorough evaluation after three or more losses [1]. It affects $1 \%$ pregnancies and is multi-factorial in origin [2]. As per Rodger L. Bick in his textbook over 500,000 women in the USA per year are affected. RPL is very important in our society and it is associated with high morbidity and mortality as well as a big psycho-social problem. As physicians we understand that pregnancy is a prothrombotic state and we should be aware that hypercoagulable states causing thrombophilia is a main cause of RPL in our society. In this editorial I want to make our colleagues more conscious of this major public health issue [3]. It is important to know that evidence from systematic reviews and meta-analysis of studies indicate that women with thromboia are not only at risk of venous thromboembolism (VTE) during pregnancy, but may also be at increase risk of common placentamediated pregnancy complications during preeclampsia, small for gestational age infants, placental abruption, miscarriage, and stillbirth [4].

The antiphospholipid syndrome (APS) is the most important treatable cause of recurrent miscarriage as well as an important cause of early onset preeclampsia and intra-uterine growth restriction [5]. Another cause have been found such as 5, 10-methyltetrahydrofolate reductase (MTHFR) mutations, Protein-S and $\mathrm{C}$ deficiencies, Factor V Leiden Mutation (FVL), Anti-thrombin III (ATIII) deficiency, and Prothrombin Gene G20210A mutation (PGM) within others [3].

The Canadian study by Marc A. Rodger et al. [4] with 7,343 women, most were Caucasian, mean age of 30.4 years, and half were nulliparous, revealed that carriers of FVL or PGM are not a significant increased risk of these pregnancy complications. Anti-thrombin III, Protein C, and Protein S and APS are more potent thrombophilias associated with obstetric complications. I found in practice of almost 20 years in Puerto Rico that most of women RPL and obstetric complications have thrombophilias related to not only APS but also MTHFR mutations and ATIII, Protein C and/or S deficiencies. I have seen cases with family history of VTE and miscarriage where no workup has been done in young adult women with RPL or pre-eclampsia. Another issue is the use of heparin or low-molecular weight heparin in this setting. This issue is well discussed in a paper of Sara A. Bennett et al. from London [2] as well as by Adel Abu-Heija [6]. Kutuk et al. [7] found that in the RPL group, $53.1 \%$ of the patients were not evaluated with standard tests; $31.9 \%$ of women were incompletely evaluated and $15 \%$ were properly evaluated. Out of 104 women screened for thrombophilia, 32 $(30.8 \%)$ were tested during pregnancy. This is sorry in this century and physicians should be more aware of this issue. Public and healthcare providers' education to change this attitude should be implemented.

An excellent review of screening patterns and recommendations have been pointed out [8] such as much controversy regarding the association of inherited thrombophilias with adverse pregnancy outcomes. The guidelines recommend doing screening if a personal or strong family history of VTE or RPL is present, but the authors found that up to $40 \%$ of physicians may screen contrary to the current guidelines. Most of the perinatologists and/or materno-fetal obstetricians and Reproductive Endocrinologists are appropriately testing patients with RPL.

Finally, I recommend to educate more the physicians, led the experts present their research papers and their experience as case reports, and go forward in the prevention and/or early detection of those hypercoagulable states mentioned above that are responsible of RPL and obstetric complications.

\section{References}

1. Practice Committee of the American Society for Reproductive Medicine (2008) Definitions of infertility and recurrent pregnancy loss. Fertil Steril 89: 1603

2. Bennett SA, Bagot CN, Arya R (2012) Pregnancy loss and thrombophilia: the elusive link. Br J Haematol 157: 529-542.

3. Bick RL (2006) Recurrent miscarriage syndrome and infertility caused by blood coagulation protein/platelet defects. In: Bick RL, Frenkel EP, Baker WF, Sarode E (Eds.), Hematological Complications in Obstetrics, Pregnancy, and Gynecology, Cambridge University Press, pp: 55-74.

4. Rodger MA, Walker MC, Smith GN, Wells PS, Ramsay T, et al. (2014) Is trombophilia associated with planceta-mediated pregnancy complictions? A prospective cohort study. Journal of Thrombosis and Haemostasis.

5. Rai RS (2002) Antiphospholipid syndrome and recurrent miscarriage. J Postgrad Med 48: 3-4.

6. Abu-Heija A (2014) Thrombophilia and Recurrent Pregnancy Loss: Is heparin still the drug of choice? Sultan Qaboos Univ Med J 14: e26-26e36.

7. Kutuk MS, Terzioglu A, Ozgun MT, Uludag S, Dolanbay M, et al. (2014) A critical analysis of low molecular weight heparin use during pregnancy in a tertiary referral centre. J Obstet Gynaecol 34: 131-134.

8. Davenport WB, Kutteh WH (2014) Inherited Thrombophilias and Adverse Pregnancy Outcomes: A Review of Screening Patterns and Recommendations. Obstet Gynecol Clin North Am 41: 133-144.

*Corresponding author: Raúl H. Morales-Borges, Ashford Institute of Hematology \& Oncology, 29 Washington Street Suite \# 107, San Juan PR 00907-1509, USA, Tel: (787) 722-0412; Fax: (787) 723-0554; E-mail: rmoralesborges@yahoo.com

Received March 01, 2014; Accepted March 04, 2014; Published March 08, 2014

Citation: Morales-Borges RH (2014) Thrombophilia and Recurrent Pregnancy Loss: Are we Still Loosing the Link at the $21^{\text {st }}$ Century? J Blood Disorders Transf 5: e115. doi: 10.4172/2155-9864.1000e115

Copyright: (c) 2014 Morales-Borges RH. This is an open-access article distributed under the terms of the Creative Commons Attribution License, which permits unrestricted use, distribution, and reproduction in any medium, provided the original author and source are credited. 